\title{
Antitumor effect of lenalidomide in malignant glioma cell lines
}

\author{
YUYA HANASHIMA $^{1}$, EMIKO SANO $^{2}$, KOICHIRO SUMI $^{1}$, YOSHINARI OZAWA $^{1}$, \\ CHIHIRO YAGI $^{1}$, JURI TATSUOKA ${ }^{1}$, SODAI YOSHIMURA ${ }^{1}$, SHUN YAMAMURO $^{1}$, \\ TAKUYA UEDA $^{2}$, TOMOHIRO NAKAYAMA ${ }^{3}$, HIROYUKI HARA ${ }^{4}$ and ATSUO YOSHINO ${ }^{1}$

\begin{abstract}
${ }^{1}$ Division of Neurosurgery, Department of Neurological Surgery, Nihon University School of Medicine, Tokyo 173-8610; Kashiwa, Chiba 277-8562; ${ }^{3}$ Division of Companion Diagnostics, Department of Pathology and Microbiology, Nihon University School of Medicine, Tokyo 173-8610; ${ }^{4}$ Division of Anatomical Science, Department of Functional Morphology, Nihon University School of Medicine, Tokyo 173-8610, Japan
\end{abstract} \\ ${ }^{2}$ Department of Computational Biology and Medical Sciences, Graduate School of Frontier Sciences, The University of Tokyo,
}

Received June 24, 2019; Accepted January 29, 2020

DOI: $10.3892 /$ or.2020.7543

\begin{abstract}
Glioblastoma is a malignant brain tumor exhibiting highly aggressive proliferation and invasion capacities. Despite treatment by aggressive surgical resection and adjuvant therapy including temozolomide and radiation therapy, patient prognosis remains poor. Lenalidomide, a derivative of thalidomide, is known to be an immunomodulatory agent that has been used to treat hematopoietic malignancies. There are numerous studies revealing an antitumor effect of lenalidomide in hematopoietic cells, but not in glioma cells. The present study aimed to demonstrate the antitumor effect of lenalidomide on malignant glioma cell lines. The growth inhibition of malignant glioma cells (A-172, AM-38, T98G, U-138MG, U-251MG, and YH-13) by lenalidomide was assessed using a Coulter counter. The mechanism of the antitumor effect of lenalidomide was examined employing a fluorescence-activated cell sorter, western blot analysis, and quantitative real-time reverse transcriptional polymerase chain reaction (RT-qPCR) in malignant glioma cell lines (A-172, AM-38). The results revealed that the number of malignant glioma cells was decreased in a concentration-dependent manner by lenalidomide. DNA flow cytometric analysis demonstrated an increase in the ratio of cells at the $\mathrm{G}_{0} / \mathrm{G}_{1}$ phase following lenalidomide treatment. Western blot analysis and RT-qPCR revealed that $\mathrm{p} 53$ activation and the expression of $\mathrm{p} 21$ were increased in glioma cells treated with lenalidomide. Western blot analysis revealed that cleavage of PARP did not occur; however, increased expression of Bax protein, cleavage of caspase- 9 and cleavage of caspase- 3 were confirmed. Analysis
\end{abstract}

Correspondence to: Dr Koichiro Sumi, Division of Neurosurgery, Department of Neurological Surgery, Nihon University School of Medicine, 30-1 Oyaguchikamicho, Itabashi-ku, Tokyo 173-8610, Japan E-mail: sumi.koichiro@nihon-u.ac.jp

Key words: malignant glioma, lenalidomide, cell cycle arrest, apoptosis, drug repositioning by FACS also supported the conclusion that little apoptosis induction occurred following lenalidomide treatment of malignant glioma cell lines. In conclusion, lenalidomide exerts an antitumor effect on glioma cells due to alterations in cell cycle distribution.

\section{Introduction}

Glioblastoma is the most common primary tumor of the central nervous system in adults. Despite treatment including maximal surgical resection, radiotherapy and temozolomide chemotherapy, overall survival (OS) of patients remains at 14.6 months $(1,2)$. Although several clinical trials have emerged as potential novel treatments, there have been few advances in treatment options during the last 3 decades.

Recently, drug repurposing has been successful in various different therapeutic fields, including those involving aspirin, sildenafil, erythromycin, minoxidil and thalidomide. Thalidomide was originally used for the treatment of morning sickness in the 1950s. However, in 1961, it was banned because of potential teratogenicity such as phocomelia. In 1999, thalidomide was found to exert an antitumor effect on multiple myeloma (3). Subsequently, it was again used and the side effects are now considered acceptable if the thalidomide is administered to patients with a life-threatening condition, such as multiple myeloma (4-7).

On the other hand, lenalidomide is a thalidomide derivative and was developed in order to reduce the side effects and enhance the antitumor effect of thalidomide. Clinically, the antitumor effect of lenalidomide was shown to be more effective than that of thalidomide in hematopoietic malignancies (8-12). Recently, lenalidomide has been widely used clinically as an antitumor drug for hematopoietic malignancies including multiple myeloma and myelodysplastic syndrome (13-15). Lenalidomide has been reported to display a multiple antitumor effect including immunological activity, an inhibitory effect on angiogenesis, a growth inhibitory effect and induction of apoptosis (16). The main antitumor mechanism of lenalidomide has been proposed to involve induction of growth arrest due to an increased expression of 
p21 (16). It was reported recently that cell cycle arrest induced by $\mathrm{p} 21$ is related to cereblon protein as a primary target of lenalidomide (17), and cereblon expression is required for the antitumor activity of lenalidomide (18).

Thalidomide has been previously reported to exert an antitumor effect on glioma cells. Several clinical trials since then have revealed an effect of thalidomide on malignant glioma patients (19-21). However, these trials failed to demonstrate an extended median survival time. An antitumor effect of lenalidomide in glioblastoma can also be expected, as lenalidomide is superior to thalidomide in cases of hematopoietic malignancies clinically. Furthermore, lenalidomide has a low molecular weight of $259.26 \mathrm{~g} / \mathrm{mol}$ and can therefore pass through the blood-brain barrier. Lenalidomide may display an antitumor effect by prolonging progression-free survival and overall survival of patients with glioblastoma, and Phase I trials using lenalidomide for central nervous system tumors were reported in 2007 and $2011(22,23)$. In these studies, lenalidomide was well tolerated in patients including children with recurrent central nervous system tumors, although the toxicity due to lenalidomide mainly involved myelosuppression and thromboembolism. Preliminary data indicated that the effect of lenalidomide was favorable. However, its effect on malignant glioma cells has remained controversial. In the present study, we aimed to elucidate the antitumor effect of lenalidomide on malignant glioblastoma cells.

\section{Materials and methods}

Materials. Lenalidomide (Celgene Corp.) was employed for the experiments. Lenalidomide was dissolved in DMSO, which was used as a control at corresponding concentrations.

Cell lines and culture. Human malignant glioma cell lines A-172 (cell no. JCRB0228; lot no. 021999), AM-38 (cell no. IFO05492; lot no. 12082003), T98G (cell no. IFO50303; lot no. 1007), U-251MG (cell no. IFO 50288; lot no. 12132002), and YH-13 (cell no. IFO50493; lot no. 1164) (purchased from Health Science Research Resources Bank), and U-138MG (cat. no. HTB-16; lot no. 1104428; purchased from American Type Culture Collection) were employed in the present study. These cells were regularly cultured in Dulbecco's modified Eagle's medium (DMEM) (Nissui Pharmaceutical) supplemented with 5\% fetal bovine serum (FBS) (Thermo Fisher Scientific, Inc.) using plastic flasks (Corning) in a humidified incubator at $37^{\circ} \mathrm{C}$ with an atmosphere containing $5 \% \mathrm{CO}_{2}$, as described previously (24).

Coulter counter assays. The growth inhibition of malignant glioma cells by lenalidomide was evaluated by counting the numbers of cells using a Z1 Coulter Counter ${ }^{\circledR}$ (Beckman Coulter). Each well was seeded at $1 \times 10^{4}$ cells in 24 plates and cultured for $24 \mathrm{~h}$. The cells were incubated in the medium with $0.1,1,10$ and $100 \mu \mathrm{M}$ of lenalidomide, respectively. After $72 \mathrm{~h}$ of exposure to the various concentrations of lenalidomide, the cells were trypsinized and counted with the cell Coulter counter. The experiments were repeated 4 times at each concentration.
Furthermore, to evaluate the underlying mechanisms of the antitumor effect of lenalidomide, we undertook further experiments employing A-172 and AM-38 human glioma cell lines. The cells were incubated for $24 \mathrm{~h}$ to achieve attachment and exposed to lenalidomide at a concentration of $10 \mu \mathrm{M}$ in the new medium.

Cell cycle distribution analysis. A-172 and AM-38 cells were harvested using $0.25 \%$ trypsin-EDTA solution (Invitrogen; Thermo Fisher Scientific, Inc.) after 0, 8, 24, 48 and $72 \mathrm{~h}$ of lenalidomide treatment, fixed in ice-cold $70 \%$ of ethanol, and treated with $0.5 \%$ of RNase A (Roche Diagnostics). The treated cells were stained with $1 \mu \mathrm{g} / \mathrm{ml}$ propidium iodide (PI) (Miltenyi Biotec) for $30 \mathrm{~min}$. The fluorescence was measured with a FACS-Calibur flow cytometer (BD Biosciences) at a wavelength of $610 \mathrm{~nm}$ (FL3). The DNA histograms were analyzed employing FlowJo software (v.9. 9. 6; BioLegend, Inc.).

Determination of apoptotic cells. The apoptosis induced by lenalidomide was evaluated by flow cytometry. The cells were incubated in the medium with $0.1,1,10$ and $100 \mu \mathrm{M}$ of lenalidomide, respectively. Following lenalidomide treatment, the cells were harvested using $0.25 \%$ trypsin-EDTA solution. After rinsing twice with phosphate-buffered saline (PBS) (-) (Nissui Pharmaceutical), the fixed cells were treated with RNase A for $1 \mathrm{~h}$, and propidium iodide (PI) and Annexin V Alexa Flour 488 conjugate (Thermo Fisher Scientific, Inc.) were added. Flow cytometry was performed with a FACS-Calibur flow cytometer (BD Biosciences). The fluorescence was detected with FL1 $(510 \mathrm{~nm})$ and FL3 $(610 \mathrm{~nm})$. The apoptosis was analyzed employing FlowJo software (BioLegend, Inc.).

Western blot analysis. Soluble protein lysates of sub-confluent glioma cells were obtained using radioimmunoprecipitation assay (RIPA) buffer (Wako Pure Chemical) containing protease inhibitors (Complet Mini, EDTA-free, Roche Diagnostics) for $20 \mathrm{~min}$ on ice. After centrifugation at $20,400 \mathrm{x} \mathrm{g}$ for $1 \mathrm{~h}$ at $4^{\circ} \mathrm{C}$, the protein content of the separated supernatants was determined by BCA assay employing a Pierce BCA protein assay kit (Thermo Scientific, Inc.). The protein (100 $\mu \mathrm{g}$ proteins) was loaded and separated by $12 \%$ polyacrylamide gel electrophoresis and then transferred onto nitrocellulose membranes (Bio-Rad Laboratories) for $1 \mathrm{~h}$ at $15 \mathrm{~V}$ with a Bio-Rad transblot (Bio-Rad Laboratories). The membrane was treated with blocking buffer (PBS/0.05\% containing $1 \%$ skimmed milk) for $1 \mathrm{~h}$ at room temperature, and subsequently treated with primary antibodies (Table I) in new blocking buffer for $24 \mathrm{~h}$ at $4^{\circ} \mathrm{C}$. After washing the membrane with washing buffer (PBS/0.05\% Tween 20), treatment with the secondary antibody (Table I) conjugated with horseradish peroxidase was undertaken for $1 \mathrm{~h}$ in room air. The transferred membrane was washed 3 times with washing buffer and visualized using LAS-4000 (GE Healthcare) after treatment with ECL Prime Western Blotting detection reagent (dilution 1:1,000) (GE Healthcare). The proteins (Bax and cleaved PARP in A-172 cells, caspase- 9 and caspase- 8 in A-172 cells, and cleaved PARP and caspase- 8 in AM- 38 cells) were probed from the same membranes. 
Table I. Primary and secondary antibodies for the western blot analysis.

\begin{tabular}{llll}
\hline Antibody name & \multicolumn{1}{c}{ Species } & Dilution & Supplier \\
\hline Primary antibody & & & \\
Anti-cereblon antibody & Rabbit polyclonal & $1: 1,000$ & $\begin{array}{l}\text { Proteintech } \\
\text { Anti-p53 antibody }\end{array}$ \\
Anti-p-p53 antibody & Mouse monoclonal & $1: 500$ & Santa Cruz Biotechnology \\
Anti-p21 antibody & Mouse monoclonal & $1: 500$ & Santa Cruz Biotechnology \\
Anti-Bcl-2-associated x & Mouse monoclonal & $1: 500$ & Santa Cruz Biotechnology \\
protein (Bax) antibody & & & Santa Cruz Biotechnology \\
Anti-caspase-9 antibody & Mouse monoclonal & $1: 1,000$ & Cell Signaling Technology \\
Anti-caspase-3 antibody & Mouse monoclonal & $1: 500$ & Santa Cruz Biotechnology \\
Anti-caspase-8 antibody & Mouse monoclonal & $1: 1,000$ & Cell Signaling Technology \\
- $\beta$-actin antibody & Mouse monoclonal & $1: 2,000$ & Wako Pure Chemical Industries, Ltd. \\
Anti-cleaved PARP antibody & Rabbit polyclonal & $1: 500$ & Cell Signaling Technology \\
Secondary antibodies & & & Sigma-Aldrich; Merck KGaA \\
Conjugated anti-mouse IgG peroxidase & & & Cell Signaling Technology \\
Conjugated anti-rabbit IgG peroxidase & & & \\
\hline
\end{tabular}

Quantification of $m R N A$ by real-time quantitative reverse transcriptional-PCR $(R T-q P C R)$. Cells were cultured in $25 \mathrm{~cm}^{2}$ collagen-coated flasks. After treatment with $10 \mu \mathrm{M}$ lenalidomide, the total RNA was extracted from the cells by employing a RNeasy Mini kit (Qiagen, Inc.). RT-qPCR was performed on a Step-One Real-time PCR system (Applied Biosystems) with SYBR-Green PCR Mix (Toyobo). The PCR conditions were as follows: 1st stage, $90^{\circ} \mathrm{C}$ for $30 \mathrm{sec}, 61^{\circ} \mathrm{C}$ for $20 \mathrm{~min}$, and $95^{\circ} \mathrm{C}$ for $1 \mathrm{~min}$; 2nd stage, 45 cycles at $95^{\circ} \mathrm{C}$ for $15 \mathrm{sec}, 55^{\circ} \mathrm{C}$ for $15 \mathrm{sec}$ and $74^{\circ} \mathrm{C}$ for $45 \mathrm{sec}$; and $3 \mathrm{rd}$ stage, $95^{\circ} \mathrm{C}$ for $15 \mathrm{sec}, 60^{\circ} \mathrm{C}$ for $1 \mathrm{~min}$, and $95^{\circ} \mathrm{C}$ for $15 \mathrm{sec}$. Glyceraldehyde-3-phosphatase dehydrogenase $(G A D P H)$ mRNA expression levels were employed as the quantitative internal control. The expression levels were calculated employing the following equations by comparing the threshold cycle $(\mathrm{Cq}): \Delta \mathrm{Cq}=\mathrm{Cq}$ of $\mathrm{p} 21$ or p53-Cq of GAPDH, $\Delta \Delta \mathrm{Cq}$ (target cell line)- $\Delta \mathrm{Cq}$ (reference cell line), and ratio $=2^{-\Delta \Delta \mathrm{Cq}}(25)$. Fold changes of the related mRNA expression were calculated by using the comparative $2^{-\Delta \Delta \mathrm{Cq}}$ method to normalize the mRNA level. The sequences of primers that were utilized for the PCR are shown in Table II.

Statistical analysis. All studies were carried out more than 3 times. The resultant data are expressed as the means $\pm \mathrm{SE}$ (standard error) and were considered significant at $\mathrm{P}<0.05$ or $\mathrm{P}<0.01$. The statistical significance was evaluated by the Student's t-test and one-way analysis of variance (ANOVA) with Tukey's post hoc test. Data analyses were performed employing the statistical software IBM SPSS statistics v.21.0 (International Business Machines Corporation).

\section{Results}

Coulter counter assay of glioma cells exposed to lenalidomide. To evaluate the antitumor effect of lenalidomide, the six malignant glioma cell lines (A-172, AM-38, T98 G, U-138MG, U-251MG, and YH-13) were incubated in medium with $0.1,1.0,10.0$ and $100.0 \mu \mathrm{M}$ of lenalidomide, respectively. Lenalidomide inhibited the cell counts of all malignant glioma cells in a concentration-dependent manner (Fig. 1). The cell growth inhibition effect tended to be confirmed at 10 and $100 \mu \mathrm{M}$ exposure to lenalidomide.

Effects of lenalidomide on the proliferation of A-172 and AM-38 cells. Hallmarks of cell cycle arrest including p53, p-p53 and p21 were determined in the glioma cells treated with lenalidomide using western blot analysis (Fig. 2A). The expression levels of p-p53 and p21 protein were increased at $4 \mathrm{~h}$ of treatment, while the expression of $\mathrm{p} 53$ protein was unchanged in the A-172 cells. In AM-38 cells, the expression of p-p53 protein was increased at $8 \mathrm{~h}$ of treatment, while the expression of p53 protein was decreased at $8 \mathrm{~h}$ of treatment and increased at $24 \mathrm{~h}$ of treatment. The expression of $\mathrm{p} 21$ protein was increased at $24 \mathrm{~h}$ after lenalidomide treatment (Fig. 2A). The RT-qPCR data showed that the $p 53$ and $p 21$ mRNA expression levels were significantly increased in the A-172 and AM-38 cells receiving $3 \mathrm{~h}$ of lenalidomide treatment (Fig. 2B). DNA flow cytometric analysis demonstrated a significantly increased population of cells in the $\mathrm{G}_{0} / \mathrm{G}_{1}$ phase at $24 \mathrm{~h}$ after treatment with lenalidomide. These findings indicated that alterations in the cell cycle distribution had occurred in the A-172 and AM-38 cells (Fig. 3A and B).

Expression of cereblon. Furthermore, to evaluate the mechanism underlying the cell cycle arrest induced by lenalidomide, we examined the expression of cereblon protein which is considered the primary target of lenalidomide. Cereblon protein was expressed in all cell lines, but the degree of expression was varied (Fig. 4). There was no obvious relationship between the expression level of cereblon and inhibition of malignant glioma due to lenalidomide.

Effects of lenalidomide on the apoptosis of the A-172 and $A M-38$ cells. To assess the apoptosis induced by lenalidomide, 
Table II. Primer sets.

\begin{tabular}{ll}
\hline Gene & \\
\hline GAPDH & \multicolumn{1}{c}{ Primer } \\
\multicolumn{1}{l}{ p53 } & Forward; 5'-CAGAACATCATCCCTGCCTCT-3' \\
& Reverse; 5'-GCTTGACAAAGTGGTCGTTGAG-3' \\
p21 & Forward; 5'-GGCCCACTTCACCGTACTAA-3' \\
& Reverse; 5'-GTGGTTTCAAGGCCAGATGT-3' \\
Bax & Forward; 5'-TGGAGACTCTCAGGGTCGAAA-3' \\
& Reverse; 5'-GGCGTTTGGAGTGGTAGAAATC-3' \\
Caspase-9 & Forward; 5'-TTTGCTTCAGGGTTTCATCC-3' \\
& Reverse; 5'-CAGTTGAAGTTGCCGTCAGA-3' \\
Caspase-3 & Forward; 5'-TTCCCAGGTTTTGTTTCCTG-3' \\
& Reverse; 5'-CCTTTCACCGAAACAGCATT-3' \\
& Forward; 5'-AGAACTGGACTGTGGCATTGAG-3' \\
& Reverse; 5'-GCTTGTCGGCATACTGTTTCAG-3'
\end{tabular}

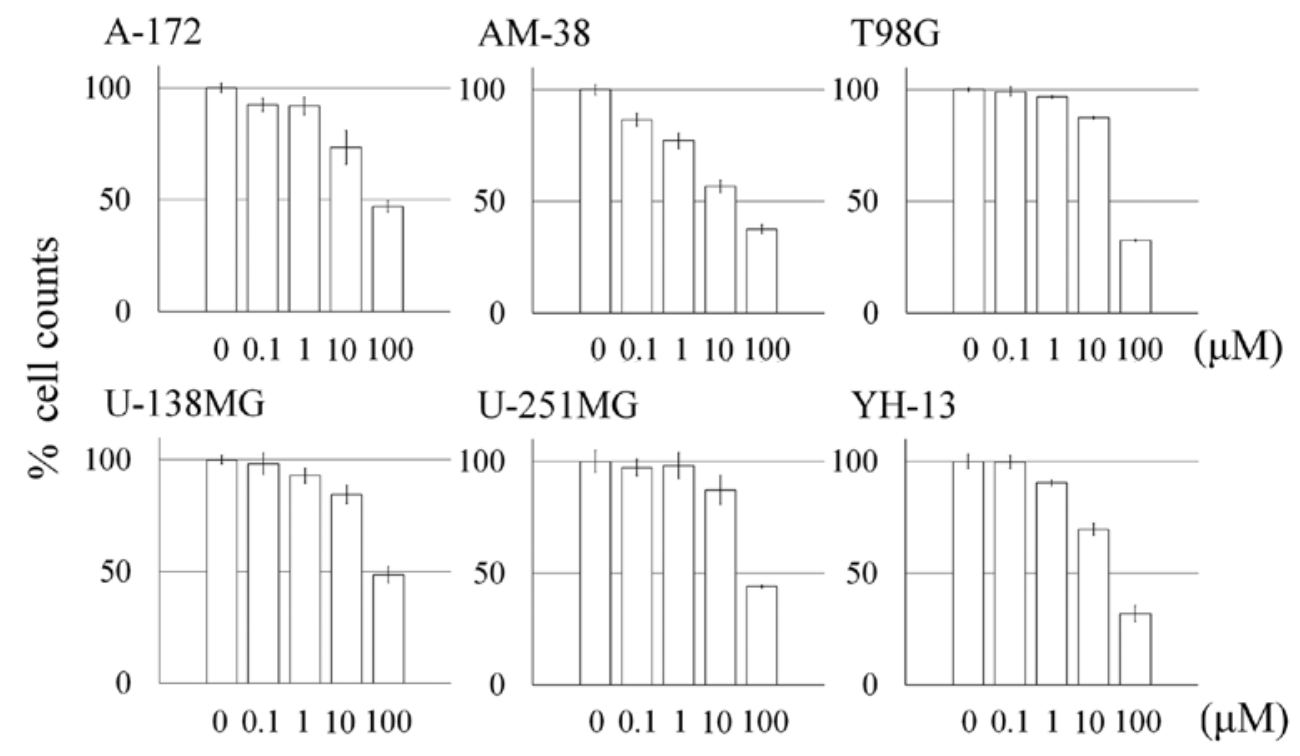

Concentration of lenalidomide

Figure 1. Percentage of the cell counts of glioma cells following treatment with lenalidomide. Six malignant glioma cell lines (A-172, AM-38, T98G, U138MG, $\mathrm{U}-251 \mathrm{MG}$ and $\mathrm{YH}-13$ ) were incubated in medium with $0.1,1.0,10.0$ and $100.0 \mu \mathrm{M}$ of lenalidomide, respectively. After $72 \mathrm{~h}$ of exposure to the various concentrations of lenalidomide, the cells were trypsinized and counted using a Z1 Coulter Counter. The number of all malignant glioma cells was inhibited in a concentration-dependent manner. Lenalidomide exerted an antitumor effect in the malignant glioma cell lines, and in most cell lines, this antitumor effect was confirmed at a concentration of $>10 \mu \mathrm{M}$. The results are expressed as the means $\pm \mathrm{SE}$.

the expression levels of apoptotic hallmark proteins including Bax, caspase-9, caspase-3, cleaved poly-ADP-ribose polymerases (PARP) and caspase- 8 were evaluated by western blot analysis. The data showed that there was little induction of apoptosis in the A-172 and AM-38 cells (Fig. 5). No band of cleaved PARP was detected, although the apoptotic hallmarks of the intrinsic pathway such as Bax and caspase-9 were accumulated over time following treatment with $10 \mu \mathrm{M}$ lenalidomide. Cleaved caspase- 9 and cleaved caspase- 3 were accumulated during the same time course. The apoptotic hallmarks of the extrinsic pathway such as caspase- 8 and cleaved caspase- 8 remained unaffected (Fig. 6). The induction of apoptosis by lenalidomide in A-172 and AM-38 cells was evaluated by flow cytometry using Annexin V/PI double staining.
This analysis revealed no increased population of early-stage apoptosis or late-phase apoptosis. After 24, 48, and $72 \mathrm{~h}$ of treatment with $0.1,1.0,10.0$, and $100.0 \mu \mathrm{M}$ of lenalidomide in the medium, the FACS data indicated that little apoptosis had occurred (Fig. 7).

\section{Discussion}

The antitumor activity of lenalidomide has been previously reported in hematopoietic cells. Kuramitsu et al demonstrated an effect of lenalidomide on the immune system in vitro and in vivo (26). Lenalidomide exerts an antitumor effect due to enhancement of the cytotoxic effect in $\mathrm{T}$ cell interferon- $\gamma$ secretion. Kuhnol et al reported that the immune reaction 
A

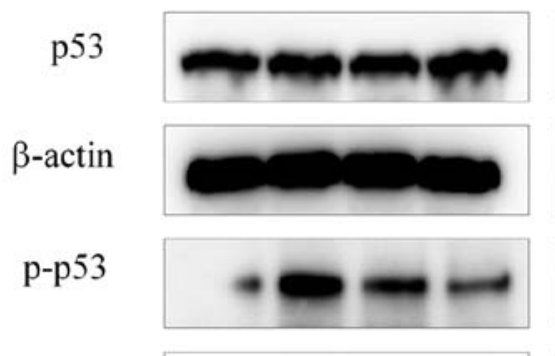

$\beta$-actin

p21
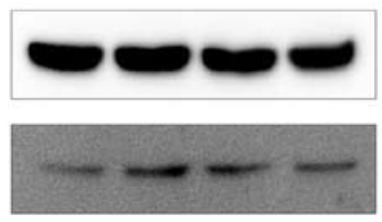

$\beta$-actin

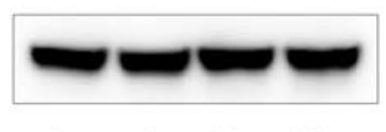

AM-38
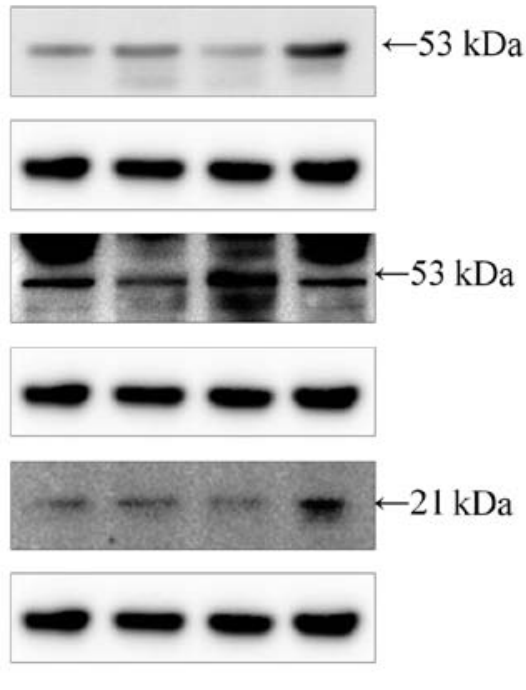
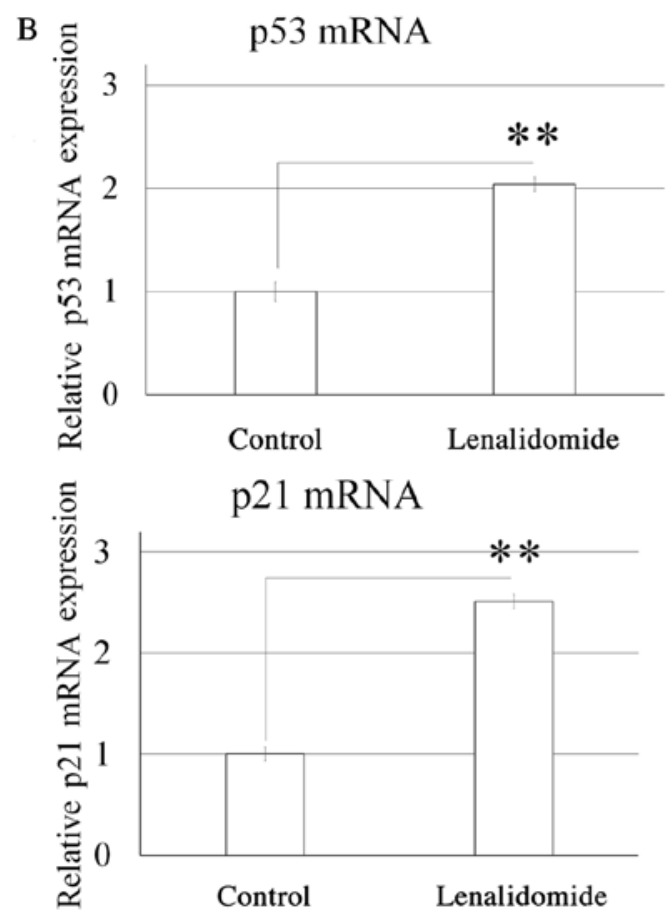
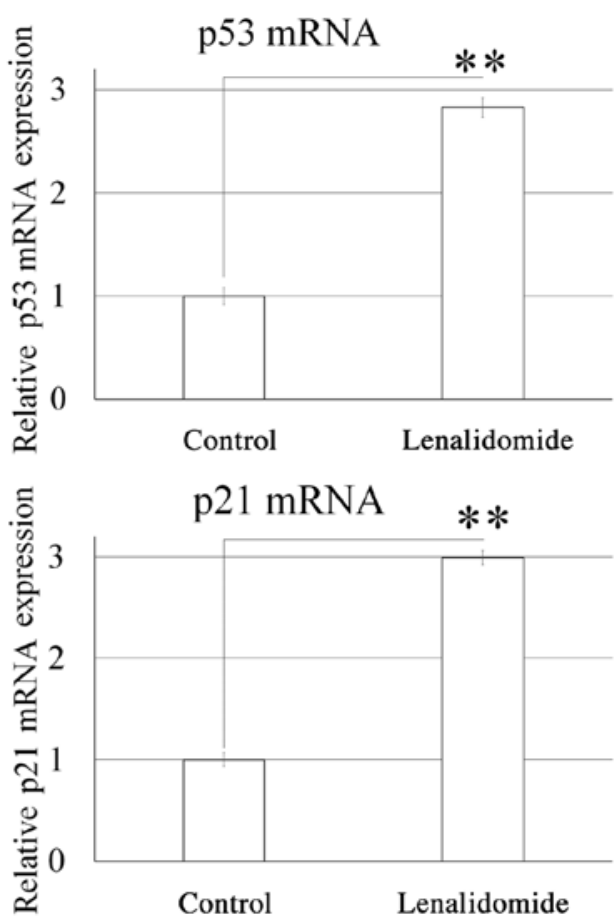

Figure 2. Effects of lenalidomide on the proliferation of A-172 and AM-38 glioma cell lines. (A) Proteins related to cell cycle arrest hallmarks including p53, phosphorylated (p)-p53 and p21 were investigated by western blot analysis at $0,4,8$ and $24 \mathrm{~h}$ after treatment with lenalidomide, respectively. The expression levels of p-p53 and p 21 proteins were increased at 4 or $8 \mathrm{~h}$ of treatment, while the expression of p53 protein remained unchanged in A-172 cells. The expression of p53 protein was decreased, and the expression of p-p53 protein was increased at $8 \mathrm{~h}$ of treatment in AM-38 cells, while, the expression of p21 protein was increased at $24 \mathrm{~h}$ after lenalidomide treatment in in the AM-38 cells. (B) The mRNA expression of $p 53$ and $p 21$, related with cell cycle arrest, was investigated by RT-qPCR. The data obtained showed that $p 53$ and $p 21 \mathrm{mRNA}$ was overexpressed at $3 \mathrm{~h}$ after lenalidomide treatment. GAPDH was employed as the internal control. The relative expression level of the genes was calculated using $2^{-\Delta \Delta C q}$ method. The results are expressed as the means $\pm \mathrm{SE}$. ${ }^{* *} \mathrm{P}<0.01$ (Student's $\mathrm{t}$-test).

was enhanced by lenalidomide in in vitro models (27). These studies evaluated the antitumor effect of immune cells induced by lenalidomide. However, no effect of lenalidomide on malignant glioma cells has yet been confirmed. We focused on the direct antitumor effects of lenalidomide, such as its influence on the cell cycle and induction of apoptosis in glioma cells. Much of the mechanisms underlying the antitumor effect in glioma cells remains unknown. It was newly discovered that lenalidomide showed a direct antitumor effect of cell cycle arrest in malignant glioma cell lines.
In the Coulter counter assays, the number of malignant glioma cells was decreased in a concentration-dependent manner. In most cell lines, an antitumor effect of lenalidomide was confirmed at a concentration of $10 \mu \mathrm{M}$.

We examined the mechanisms underlying the antitumor effect of lenalidomide using A-172 and AM-38 glioma cell lines. The glioma cells were exposed to lenalidomide, and we evaluated the expression levels of various proteins employing western blot analysis, flow cytometric analysis and mRNA expression analysis using the RT-qPCR to 


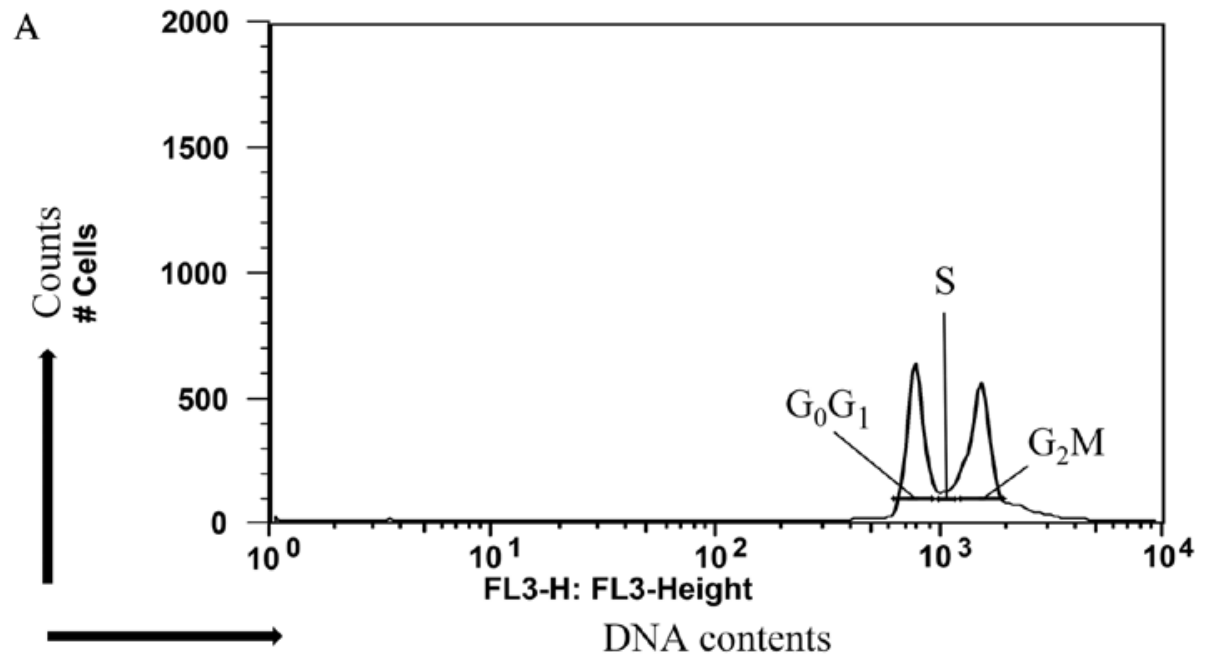

A-172

Control

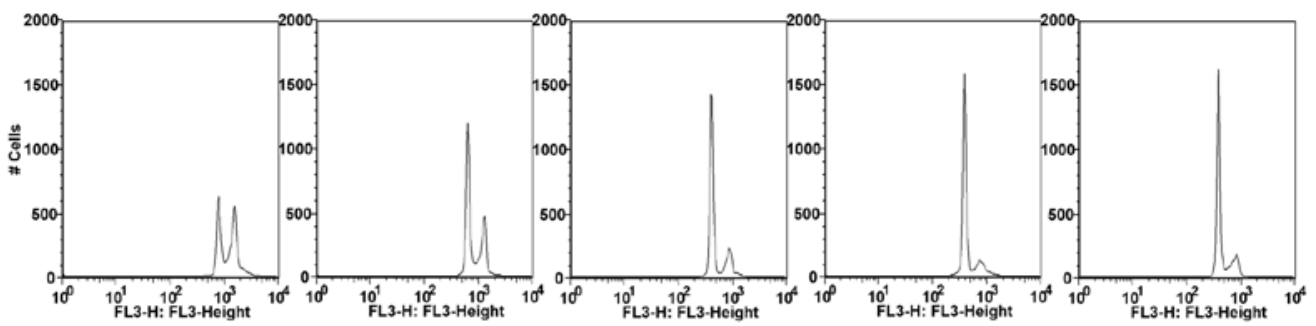

Lenalidomide

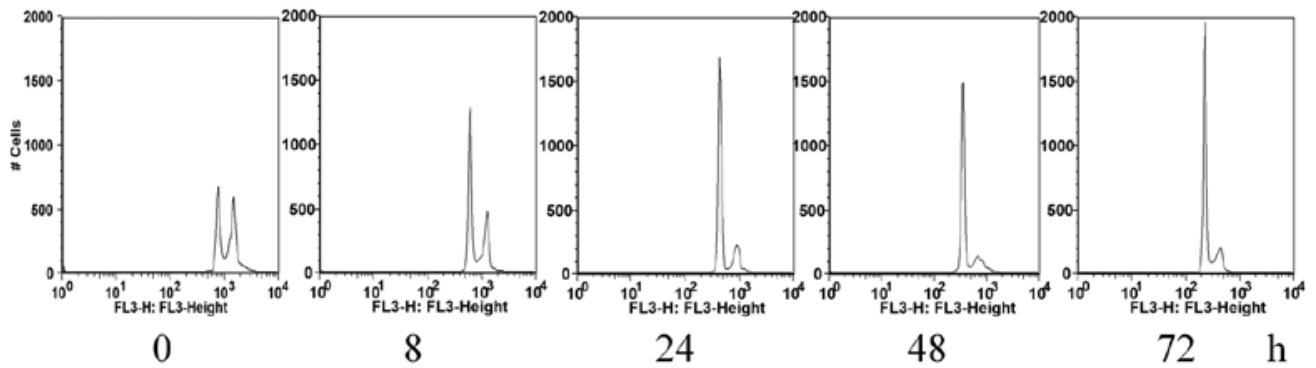

AM-38

Control
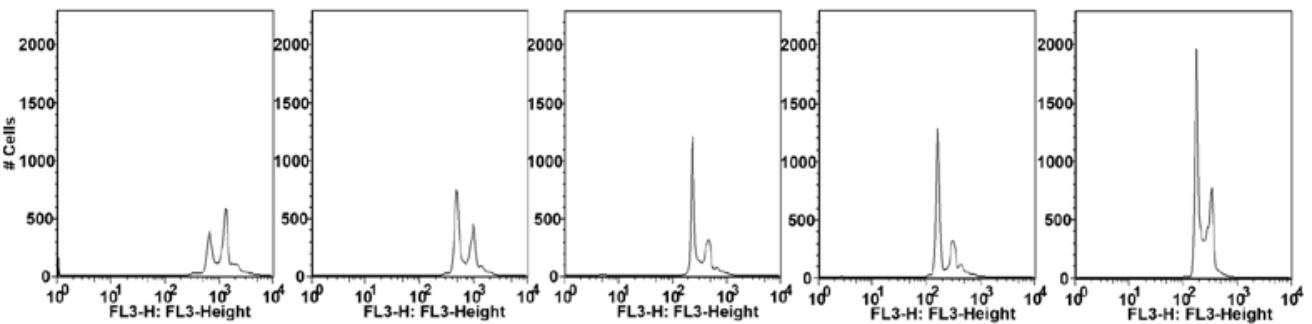

Lenalidomide
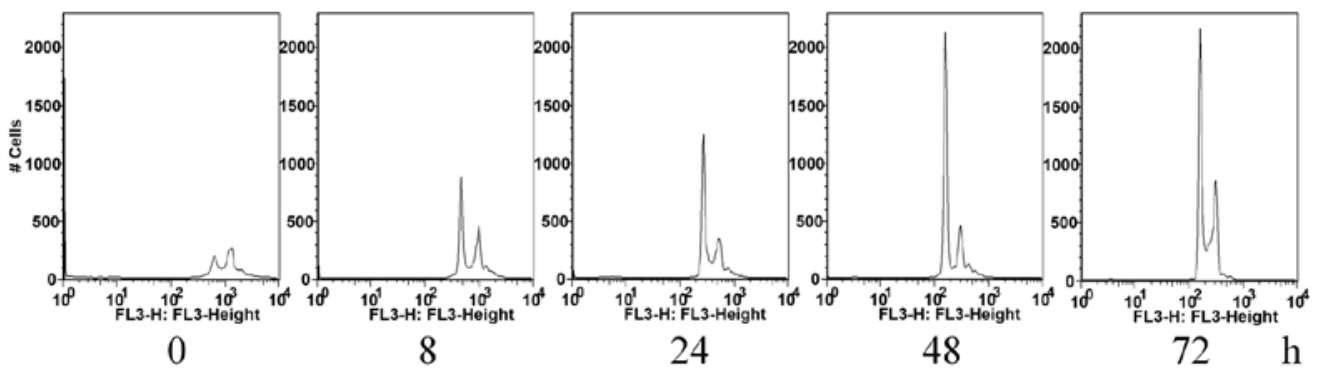

Figure 3. (A and B) Cell cycle distribution analysis of A-172 and AM-38 cells treated with $10 \mu \mathrm{M}$ of lenalidomide at $0,8,24,48$, and $72 \mathrm{~h}$. A-172 and AM-38 were used for this experiment. These cells were treated with $10 \mu \mathrm{M}$ of lenalidomide for $0,8,24,48$, and $72 \mathrm{~h}$. A group treated with the same amount of DMSO as that in which the lenalidomide was dissolved was used as the control. The histogram data revealed an increase in population of cells in the $\mathrm{G}_{0} / \mathrm{G}_{1}$ phase following lenalidomide treatment $\left({ }^{*} \mathrm{P}<0.05,{ }^{* * *} \mathrm{P}<0.01\right)$. 

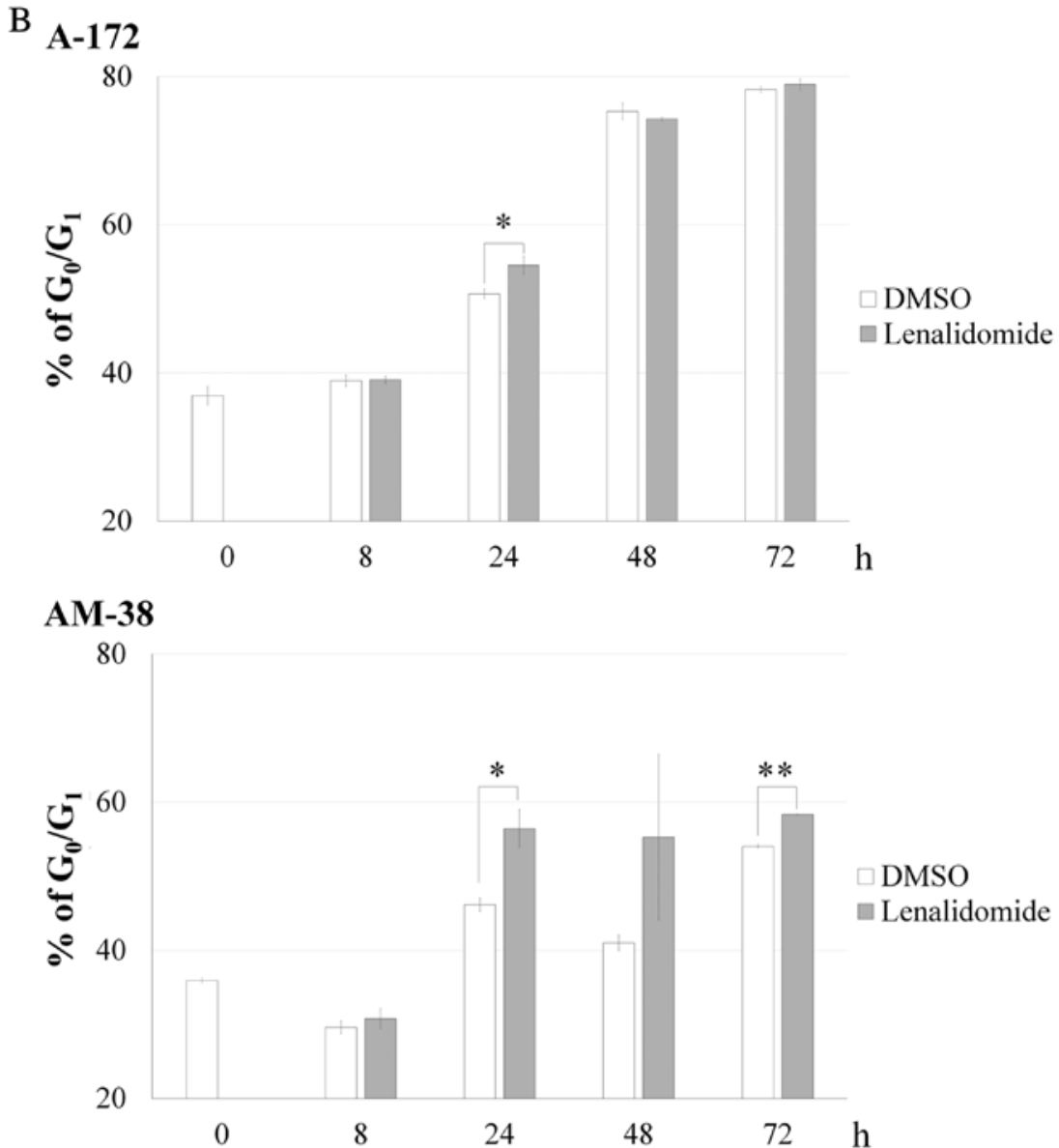

Figure 3. Continued. (A and B) Cell cycle distribution analysis of A-172 and AM-38 cells treated with $10 \mu \mathrm{M}$ of lenalidomide at $0,8,24,48$, and $72 \mathrm{~h}$. A-172 and AM-38 were used for this experiment. These cells were treated with $10 \mu \mathrm{M}$ of lenalidomide for $0,8,24,48$, and $72 \mathrm{~h}$. A group treated with the same amount of DMSO as that in which the lenalidomide was dissolved was used as the control. The histogram data revealed an increase in population of cells in the $\mathrm{G}_{0} / \mathrm{G}_{1}$ phase following lenalidomide treatment $\left({ }^{*} \mathrm{P}<0.05,{ }^{* *} \mathrm{P}<0.01\right)$.

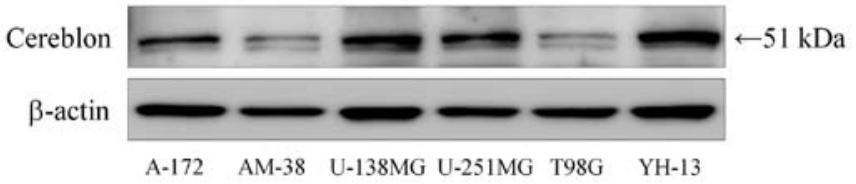

Figure 4. Expression of cereblon. The expression of cereblon in six malignant glioma cells (A-172, AM-38, T98G, U138MG, U-251MG and YH-13) was evaluated by western blot analysis. $\beta$-actin was employed as the internal control. Cereblon proteins were expressed in all the glioma cells

observe alterations occurring in cell cycle distribution and apoptosis.

The concentration utilized for our experiments was $10 \mu \mathrm{M}$, since our results indicated that the antitumor effect of lenalidomide was observed at a concentration less than $10 \mu \mathrm{M}$. In addition, Warren's phase I trial demonstrated that the safety dose of lenalidomide was in the range of 2.5 to $116 \mathrm{mg} / \mathrm{m}^{2}(23)$. Following administration of $20 \mathrm{mg} / \mathrm{m}^{2}$ of lenalidomide, the blood concentration in the body rises to approximately $2.2 \mu \mathrm{M}$ with a peak at $1 \mathrm{~h}(28)$. We inferred that $10 \mu \mathrm{M}$ of lenalidomide was reasonable for clinical use without harmful side effects.

In previous research concerning lenalidomide employing hematopoietic cancer cells, various antitumor effects including a growth inhibition effect, induction of apoptosis,

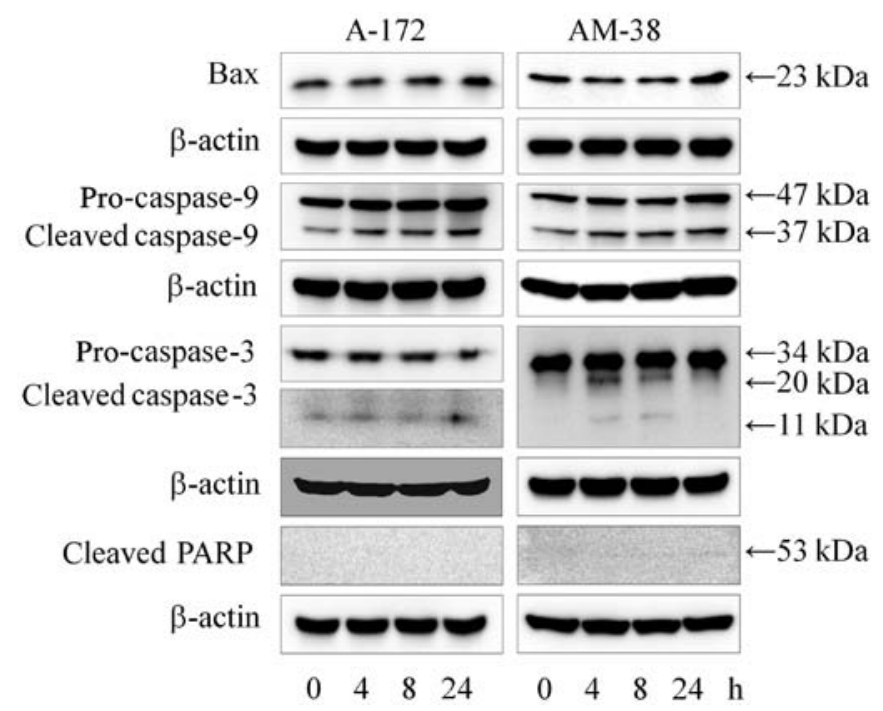

Figure 5. Effects of lenalidomide on the intrinsic pathway of apoptosis Proteins related with the intrinsic apoptotic pathway hallmarks including Bax, caspase- 9 and caspase- 3 were investigated by western blot analysis at 0 , 4,8 , and $24 \mathrm{~h}$ after lenalidomide treatment, respectively. The data obtained revealed that the expression of Bax protein was increased at $24 \mathrm{~h}$ in the A-172 and AM-38 cells. Cleavage of caspase- 9 protein was increasingly expressed in the time series following 4,8 , and $24 \mathrm{~h}$ of treatment. The expression of caspase- 3 protein cleavage was increased at $24 \mathrm{~h}$ of treatment in the A-172 cells, and increased at 4 and $8 \mathrm{~h}$ of treatment in the AM-38 cells. However, cleavage of PARP was not confirmed. PARP, poly(ADP-ribose) polymerase. 


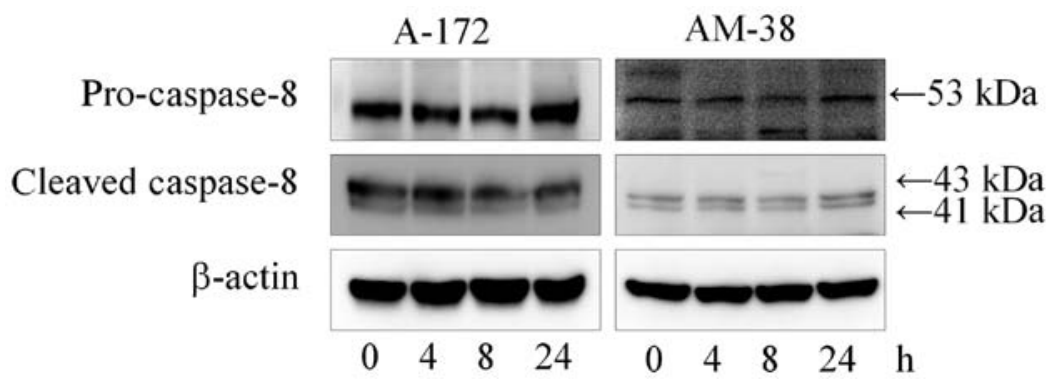

Figure 6. Effects of lenalidomide on the extrinsic pathway of apoptosis. Proteins related with the extrinsic apoptotic pathway hallmarks including caspase-8 were investigated by western blot analysis at $0,4,8$, and $24 \mathrm{~h}$ after lenalidomide treatment, respectively. The data obtained revealed that the expression of caspase- 8 protein and degree of cleavage remained unchanged until $24 \mathrm{~h}$ after lenalidomide treatment.
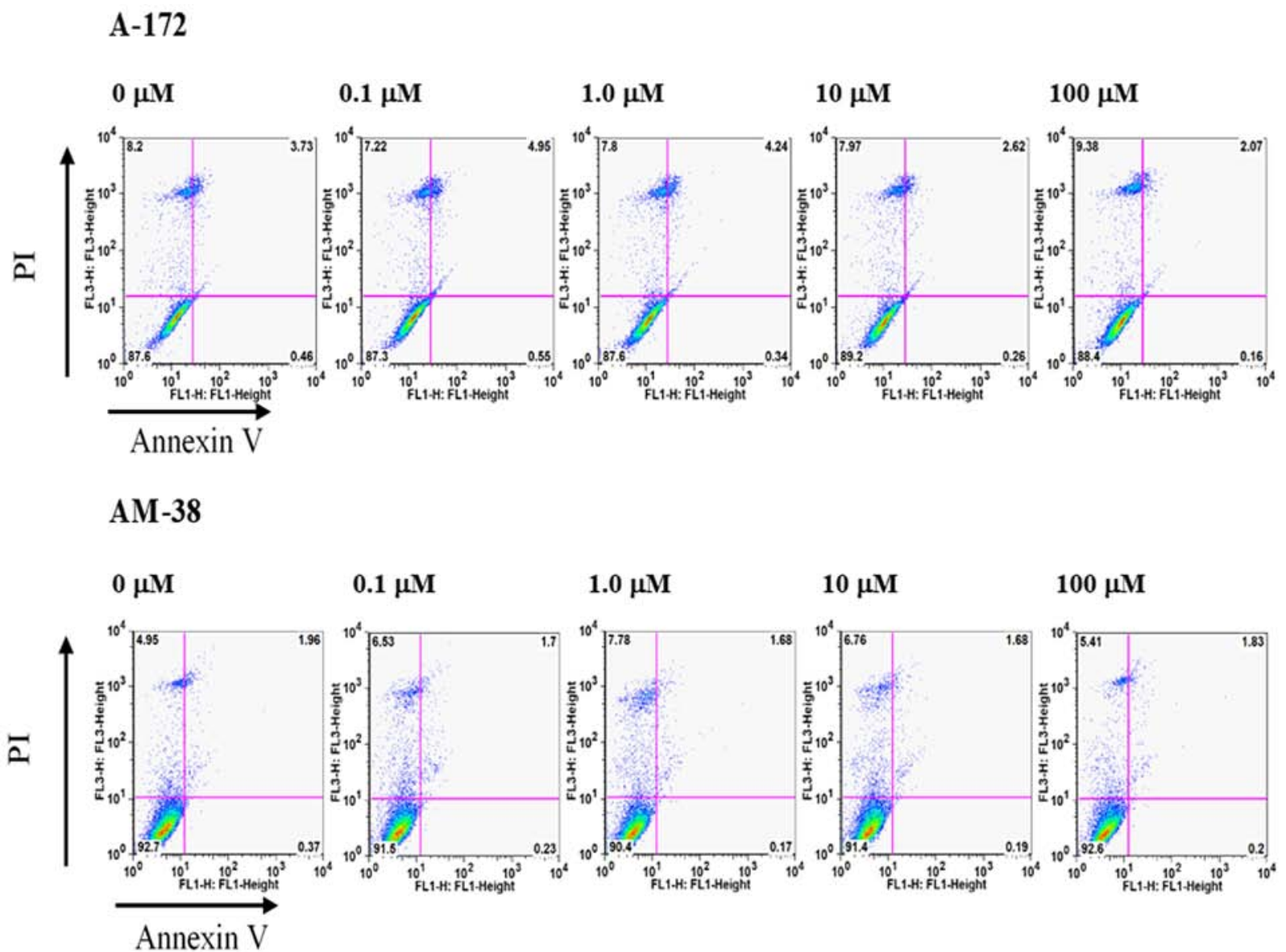

Figure 7. Assessment of apoptotic cells. The induction of apoptosis by lenalidomide in A-172 and AM-38 cells was evaluated by flow cytometry using Annexin V/PI double staining. The data obtained revealed that there were no marked changes after $72 \mathrm{~h}$ of lenalidomide treatment, in the medium without lenalidomide and with $0.1,1.0,10.0$ and $100.0 \mu \mathrm{M}$ of lenalidomide, respectively. These findings indicated that little apoptosis had occurred.

anti-angiogenic activity and immunological activity were observed $(16,29)$. In addition, induction of apoptosis was found to be related to caspase- 3 activation. In addition to these direct antitumor effects, anti-angiogenesis mediated by suppression of basic fibroblast growth factor (bFGF) and vascular endothelial growth factor (VEGF) was described $(29,30)$.

In glioma cells, we confirmed that phosphorylated p53 and functional p53 were activated after $4 \mathrm{~h}$ of lenalidomide treatment based on western blot analysis. In the present study, we investigated whether the p53/p21 pathway was activated after treatment with lenalidomide, and it was found that increased p53 and p21 protein expression induced cell cycle arrest in the glioma cells. Fecteau et al and Escoubet-Lozach et al reported that activation of p21 occurred after treatment with lenalidomide; however, functional p53 was not correlated with p21 activation in multiple myeloma cells and chronic lymphocytic leukemia cells (18). In hematopoietic cancer cells, the expression of p21 protein was increased even when p53 protein was knocked out and loading with lenalidomide treatment was undertaken (31). These observations indicated that the activation of p21 and functional p53 may be independent in hematopoietic cancer cells. In glioma cells, it seemed difficult to conclude that p21 and p53 were dependent; however, lenalidomide did induce an increased expression 
of $\mathrm{p} 21, \mathrm{p} 53$, and phosphorylated p53 and cell cycle arrest occurred.

We found that cereblon protein was expressed in all six glioma cell lines. Recently, it was reported that cereblon is a target protein for thalidomide, lenalidomide, and its derivatives (32-34). In hematopoietic malignancies, it was suggested that the expression level of cereblon regulates the antitumor effect via p21 (18). We investigated the expression of cereblon in glioma cells employing western blot analysis. It was difficult to establish the precise relationship between the expression level of cereblon and the antitumor effect. In order to investigate whether cereblon plays a crucial role in the antitumor effect mediated by lenalidomide, research using a glioma cell line with knockdown of cereblon will be carried out.

However, cereblon, a key target protein for lenalidomide, was expressed in the glioma cells. Previous studies have shown that lenalidomide directly binds cereblon and promotes the recruitment of Ikaros (IKZF1) and Aiolos (IKZF3) to the E3 complex containing cereblon. The complex of cereblon with IKZF1 and IKZF4 leads to ubiquitylation and degradation (35-37). In the future, we believe that it will also be necessary to investigate the protein levels of IKZF1 and IKZF3.

We were unable to confirm that lenalidomide exhibited apoptosis-inducing effects in the glioma cells. Previously, it was demonstrated that lenalidomide induced apoptosis in multiple myeloma cells (38). In particular, lenalidomide activated the intrinsic pathway in mantle cell lymphoma cells (39). We hypothesized that lenalidomide may induce apoptosis in glioma cells as well, and investigated the expression changes in apoptosis-related proteins using western blot analysis. However, in the glioma cells, apoptosis was not clearly observed. Western blot analysis showed that apoptotic hallmarks of the intrinsic pathway such as Bax, cleaved-caspase- 9 , and cleaved-caspase-3 were increased in the A-172 and AM-38 cells. Although the proteins related to intrinsic apoptosis were activated, cleavage of PARP was not accumulated. In addition, there was no change in the expression of the extrinsic pathway such as caspase- 8 during the treatment time courses. The FACS data revealed that only a few glioma cells were induced to undergo apoptosis. Lenalidomide is known to be an immunomodulatory agent that has been used to treat hematopoietic malignancies (8-12). It has been frequently reported that lenalidomide exhibits an antitumor effect in hematopoietic cells, but in glioma cells, the situation remains more controversial. The present study was designed to investigate the direct antitumor effect of lenalidomide on malignant glioma cell lines including cell cycle arrest and apoptosis induction. The findings of previous studies indicated that lenalidomide exerted an antitumor effect on gliomas especially enhancement of immune reactions such as interferon secretion from $T$ cells $(26,27)$.

We used a Coulter counter for cell counts. However, the Coulter counter evaluates only the number of cells present, not the viable cells. For proliferation or cell viability assays, the MTT and ATP assays should be employed. We plan to perform further studies using these assays. Our findings were not sufficient to yield a conclusive picture concerning the mechanism of action, and in vivo experiments will also need to be undertaken in the future. Additionally, the effective concentration for an antitumor effect remains to be further evaluated in in vivo experiments. In the present study, we examined the antitumor effects of single-use lenalidomide, but not any combination use involving chemotherapy such as with alkylating agents. We need to confirm whether the effect of lenalidomide in combination use may be more effective in the case of glioma cells. Lenalidomide is becoming a key drug in the guidelines for the treatment of hematopoietic cancer including multiple myeloma (15). Several studies have shown that the combination use of lenalidomide with alkylating agents or dexamethasone can be more effective in hematopoietic cancers, and the chemotherapy regimens for hematopoietic cancers usually employ lenalidomide combined with alkylating agents, such as melphalan and cyclophosphamide, and dexamethasone $(11,14)$. The standard protocol of the chemotherapy for glioblastoma also includes temozolomide, which is an alkylating agent. Furthermore, dexamethasone is often used in the postoperative management of glioblastoma (40). We speculate that the combination use of lenalidomide with temozolomide and dexamethasone may have a more potent effect in glioma patients, and this must be further researched.

In conclusion, lenalidomide displays an antitumor effect in malignant glioma cells. It induced increased expression of p21 and p53 and cell cycle arrest did occur, while there was little effect on apoptosis induction in the glioma cells.

\section{Acknowledgements}

Some parts of the present study have been included in a Japanese-language thesis submitted for the Ph.D. degree of Yuya Hanashima at Nihon University School of Medicine (Tokyo, Japan).

\section{Funding}

This research study was supported in part by a grant from the Health Sciences Research Institute, Inc. (Yokohama, Japan) for the Division of Companion Diagnostics, Department of Pathology and Microbiology, Nihon University School of Medicine (Tokyo, Japan).

\section{Availability of data and materials}

All data and materials during the study are available from the corresponding author on reasonable request.

\section{Authors' contributions}

YH and AY designed the study. YH, ES and KS collected the data and drafted the manuscript. YH, ES, YO, CY, JT, SoY and ShY performed the in vitro experiments. $\mathrm{YH}$ analyzed and interpreted the data and performed the statistical analyses. TN, $\mathrm{TU}, \mathrm{HH}$ and $\mathrm{AY}$ reviewed the manuscript, designed the figures and tables. All authors read and approved the manuscript and agree to be accountable for all aspects of the research in ensuring that the accuracy or integrity of any part of the work are appropriately investigated and resolved.

\section{Ethics approval and consent to participate}

Not applicable. 


\section{Patient consent for publication}

Not applicable.

\section{Competing interests}

The authors declare that they have no competing interests.

\section{References}

1. Stupp R, Hegi ME, Mason WP, van den Bent MJ, Taphoorn MJ, Janzer RC, Ludwin SK, Allgeier A, Fisher B, Belanger $\mathrm{K}$, et al: Effects of radiotherapy with concomitant and adjuvant temozolomide versus radiotherapy alone on survival in glioblastoma in a randomised phase III study: 5-year analysis of the EORTC-NCIC trial. Lancet Oncol 10: 459-466, 2009.

2. Stupp R, Mason WP, van den Bent MJ, Weller M, Fisher B, Taphoorn MJ, Belanger $\mathrm{K}$, Brandes AA, Marosi C, Bogdahn U, et al: Radiotherapy plus concomitant and adjuvant temozolomide for glioblastoma. N Engl J Med 352: 987-996, 2005 .

3. Singhal S, Mehta J, Desikan R, Ayers D, Roberson P, Eddlemon P, Munshi N, Anaissie E, Wilson C, Dhodapkar M, et al: Antitumor activity of thalidomide in refractory multiple myeloma. N Engl J Med 341: 1565-1571, 1999.

4. Palumbo A, Bringhen S, Caravita T, Merla E, Capparella V, Callea V, Cangialosi C, Grasso M, Rossini F, Galli M, et al Oral melphalan and prednisone chemotherapy plus thalidomide compared with melphalan and prednisone alone in elderly patients with multiple myeloma: Randomised controlled trial. Lancet 367: 825-831, 2006.

5. Facon T, Mary JY, Hulin C, Benboubker L, Attal M, Pegourie B, Renaud M, Harousseau JL, Guillerm G, Chaleteix C, et al: Melphalan and prednisone plus thalidomide versus melphalan and prednisone alone or reduced-intensity autologous stem cell transplantation in elderly patients with multiple myeloma (IFM 99-06): A randomised trial. Lancet 370: 1209-1218, 2007.

6. Waage A, Gimsing P, Fayers P, Abildgaard N, Ahlberg L, Björkstrand B, Carlson K, Dahl IM, Forsberg K, Gulbrandsen N, et al: Melphalan and prednisone plus thalidomide or placebo in elderly patients with multiple myeloma. Blood 116: 1405-1412, 2010.

7. Wijermans P, Schaafsma M, Termorshuizen F, Ammerlaan R, Wittebol S, Sinnige H, Zweegman S, van Marwijk Kooy M, van der Griend R, Lokhorst $\mathrm{H}$, et al: Phase III study of the value of thalidomide added to melphalan plus prednisone in elderly patients with newly diagnosed multiple myeloma: The HOVON 49 study. J Clin Oncol 28: 3160-3166, 2010.

8. Benboubker L, Dimopoulos MA, Dispenzieri A, Catalano J, Belch AR, Cavo M, Pinto A, Weisel K, Ludwig H, Bahlis N, et al: Lenalidomide and dexamethasone in transplant-ineligible patients with myeloma. N Engl J Med 371: 906-917, 2014.

9. Fenaux P, Giagounidis A, Selleslag D, Beyne-Rauzy O, Mufti G, Mittelman M, Muus P, Te Boekhorst P, Sanz G, Del Cañizo C, et al: A randomized phase 3 study of lenalidomide versus placebo in RBC transfusion-dependent patients with Low-/Intermediate-1-risk myelodysplastic syndromes with del5q. Blood 118: 3765-3776, 2011

10. Gay F, Hayman SR, Lacy MQ, Buadi F, Gertz MA, Kumar S, Dispenzieri A, Mikhael JR, Bergsagel PL, Dingli D, et al: Lenalidomide plus dexamethasone versus thalidomide plus dexamethasone in newly diagnosed multiple myeloma: A comparative analysis of 411 patients. Blood 115: 1343-1350, 2010.

11. Stadtmauer EA, Weber DM, Niesvizky R, Belch A, Prince MH, San Miguel JF, Facon T, Olesnyckyj M, Yu Z, Zeldis JB, et al: Lenalidomide in combination with dexamethasone at first relapse in comparison with its use as later salvage therapy in relapsed or refractory multiple myeloma. Eur J Haematol 82 426-432, 2009.

12. Zonder JA, Crowley J, Hussein MA, Bolejack V, Moore DF Sr, Whittenberger BF, Abidi MH, Durie BG and Barlogie B: Lenalidomide and high-dose dexamethasone compared with dexamethasone as initial therapy for multiple myeloma: A randomized Southwest Oncology Group trial (S0232). Blood 116: 5838-5841, 2010.
13. Knop S, Gerecke C, Liebisch P, Topp MS, Platzbecker U, Sezer O, Vollmuth C, Falk K, Glasmacher A, Maeder U, et al: Lenalidomide, adriamycin, and dexamethasone (RAD) in patients with relapsed and refractory multiple myeloma: A report from the German Myeloma Study Group DSMM (Deutsche Studiengruppe Multiples Myelom). Blood 113: 4137-4143, 2009.

14. Schey SA, Morgan GJ, Ramasamy K, Hazel B, Ladon D, Corderoy S, Jenner M, Phekoo K, Boyd K and Davies FE: The addition of cyclophosphamide to lenalidomide and dexamethasone in multiply relapsed/refractory myeloma patients; a phase I/II study. Br J Haematol 150: 326-333, 2010.

15. Palumbo A, Hajek R, Delforge M, Kropff M, Petrucci MT, Catalano J, Gisslinger H, Wiktor-Jedrzejczak W, Zodelava M, Weisel K, et al: Continuous lenalidomide treatment for newly diagnosed multiple myeloma. N Engl J Med 366: 1759-1769, 2012.

16. Hideshima T, Chauhan D, Shima Y, Raje N, Davies FE, Tai YT, Treon SP, Lin B, Schlossman RL, Richardson P, et al: Thalidomide and its analogs overcome drug resistance of human multiple myeloma cells to conventional therapy. Blood 96: 2943-2950, 2000.

17. Lopez-Girona A, Mendy D, Ito T, Miller K, Gandhi AK, Kang J, Karasawa S, Carmel G, Jackson P, Abbasian M, et al: Cereblon is a direct protein target for immunomodulatory and antiproliferative activities of lenalidomide and pomalidomide. Leukemia 26: 2326-2335, 2012

18. Fecteau JF, Corral LG, Ghia EM, Gaidarova S, Futalan D, Bharati IS, Cathers B, Schwaederlé M, Cui B, Lopez-Girona A, et al: Lenalidomide inhibits the proliferation of CLL cells via a cereblon/p21(WAF1/Cip1)-dependent mechanism independent of functional p53. Blood 124: 1637-1644, 2014.

19. Fine HA, Figg WD, Jaeckle K, Wen PY, Kyritsis AP, Loeffler JS, Levin VA, Black PM, Kaplan R, Pluda JM and Yung WK: Phase II trial of the antiangiogenic agent thalidomide in patients with recurrent high-grade gliomas. J Clin Oncol 18: 708-715, 2000.

20. Giglio P, Dhamne M, Hess KR, Gilbert MR, Groves MD, Levin VA, Kang SL, Ictech SE, Liu V, Colman H, et al: Phase 2 trial of irinotecan and thalidomide in adults with recurrent anaplastic glioma. Cancer 118: 3599-3606, 2012.

21. Penas-Prado M, Hess KR, Fisch MJ, Lagrone LW, Groves MD Levin VA, De Groot JF, Puduvalli VK, Colman H, Volas-Redd G, et al:MD Anderson Community Clinical Oncology Program; Brain Tumor Trials Collaborative: Randomized phase II adjuvant factorial study of dose-dense temozolomide alone and in combination with isotretinoin, celecoxib, and/or thalidomide for glioblastoma. Neuro Oncol 17: 266-273, 2015.

22. Fine HA, Kim L, Albert PS, Duic JP, Ma H, Zhang W, Tohnya T, Figg WD and Royce C: A phase I trial of lenalidomide in patients with recurrent primary central nervous system tumors. Clin Cancer Res 13: 7101-7106, 2007.

23. Warren KE, Goldman S, Pollack IF, Fangusaro J, Schaiquevich P, Stewart CF, Wallace D, Blaney SM, Packer R, Macdonald T, et al: Phase I trial of lenalidomide in pediatric patients with recurrent, refractory, or progressive primary CNS tumors: Pediatric Brain Tumor Consortium study PBTC-018. J Clin Oncol 29: 324-329, 2011.

24. Ochiai Y, Sano E, Okamoto Y, Yoshimura S, Makita K, Yamamuro S, Ohta T, Ogino A, Tadakuma H, Ueda T, et al: Efficacy of ribavirin against malignant glioma cell lines: Follow-up study. Oncol Rep 39: 537-544, 2018.

25. Livak KJ and Schmittgen TD: Analysis of relative gene expression data using real-time quantitative PCR and the 2(-Delta Delta C(T)) method. Methods 25: 402-408, 2001.

26. Kuramitsu S, Ohno M, Ohka F, Shiina S, Yamamichi A, Kato A, Tanahashi K, Motomura K, Kondo G, Kurimoto M, et al: Lenalidomide enhances the function of chimeric antigen receptor $\mathrm{T}$ cells against the epidermal growth factor receptor variant III by enhancing immune synapses. Cancer Gene Ther 22: 487-495, 2015.

27. Kühnöl CD, Staege MS and Kramm CM: Lenalidomide in an in vitro dendritic cell model for malignant gliomas. Anticancer Agents Med Chem 16: 1468-1473, 2016.

28. Chen N,Zhou S and Palmisano M: Clinical pharmacokinetics and pharmacodynamics of Lenalidomide. Clin Pharmacokinet 56: 139-152, 2017.

29. D'Amato RJ, Loughnan MS, Flynn E and Folkman J: Thalidomide is an inhibitor of angiogenesis. Proc Natl Acad Sci USA 91: 4082-4085, 1994.

30. Rao KV: Lenalidomide in the treatment of multiple myeloma. Am J Health Syst Pharm 64: 1799-1807, 2007. 
31. Escoubet-Lozach L, Lin IL, Jensen-Pergakes K, Brady HA Gandhi AK, Schafer PH, Muller GW, Worland PJ, Chan KW and Verhelle D: Pomalidomide and lenalidomide induce p21 WAF-1 expression in both lymphoma and multiple myeloma through a LSD1mediated epigenetic mechanism. Cancer Res 69: 7347-7356, 2009.

32. Holstein SA, Hillengass J and McCarthy PL: Next-generation drugs targeting the cereblon ubiquitin ligase. J Clin Oncol 36: 2101-2104, 2018

33. Tao J, Yang $\mathbf{J}$ and $\mathrm{Xu}$ G: The interacting domains in cereblon differentially modulate the immunomodulatory drug-mediated ubiquitination and degradation of its binding partners. Biochem Biophys Res Commun 507: 443-449, 2018.

34. Zheng J, Sha Y, Roof L, Foreman O, Lazarchick J, Venkta JK, Kozlowski C, Gasparetto C, Chao N, Ebens A, et al: Pan-PIM kinase inhibitors enhance Lenalidomide's anti-myeloma activity via cereblon-IKZF1/3 cascade. Cancer Lett 440-441: 1-10, 2019.

35. Krönke J, Udeshi ND, Narla A, Grauman P, Hurst SN, McConkey M, Svinkina T, Heckl D, Comer E, Li X, et al: Lenalidomide causes selective degradation of IKZF1 and IKZF3 in multiple myeloma cells. Science 343: 301-305, 2014.

36. Lu G, Middleton RE, Sun H, Naniong M, Ott CJ, Mitsiades CS, Wong KK, Bradner JE and Kaelin WG Jr: The myeloma drug lenalidomide promotes the cereblon-dependent destruction of Ikaros proteins. Science 343: 305-309, 2014.
37. Mori T, Ito T, Liu S, Ando H, Sakamoto S, Yamaguchi $\mathrm{Y}$, Tokunaga E, Shibata N, Handa H and Hakoshima T: Structural basis of thalidomide enantiomer binding to cereblon. Sci Rep 8: 1294-1294, 2018.

38. Yao R, Han D, Sun X, Xie Y, Wu Q, Fu C, Yao Y, Li H, Li Z and $\mathrm{Xu} \mathrm{K}$ : Scriptaid inhibits cell survival, cell cycle, and promotes apoptosis in multiple myeloma via epigenetic regulation of $\mathrm{p} 21$. Exp Hematol 60: 63-72, 2018.

39. Qian Z, Zhang L, Cai Z, Sun L, Wang H, Yi Q and Wang M: Lenalidomide synergizes with dexamethasone to induce growth arrest and apoptosis of mantle cell lymphoma cells in vitro and in vivo. Leuk Res 35: 380-386, 2011.

40. Pitter KL, Tamagno I, Alikhanyan K, Hosni-Ahmed A Pattwell SS, Donnola S, Dai C, Ozawa T, Chang M, Chan TA, et al: Corticosteroids compromise survival in glioblastoma. Brain 139: 1458-1471, 2016

(i) $\odot$ This work is licensed under a Creative Commons Attribution-NonCommercial-NoDerivatives 4.0 International (CC BY-NC-ND 4.0) License. 